\title{
AGL15 Controls the Embryogenic Reprogramming of Somatic Cells in Arabidopsis through the Histone Acetylation-Mediated Repression of the miRNA Biogenesis Genes
}

\author{
Katarzyna Nowak *, Joanna Morończyk, Anna Wójcik® and Małgorzata D. Gaj $(\mathbb{D}$ \\ Institute of Biology, Biotechnology and Environmental Protection, Faculty of Natural Sciences, \\ University of Silesia in Katowice, 40-007 Katowice, Poland; joanna.moronczyk@us.edu.pl (J.M.); \\ anna.wojcik@us.edu.pl (A.W.); malgorzata.gaj@us.edu.pl (M.D.G.) \\ * Correspondence: katarzyna.nowak@us.edu.pl; Tel.: +48-32-2009-428
}

Received: 26 August 2020; Accepted: 11 September 2020; Published: 14 September 2020

check for updates

\begin{abstract}
The embryogenic transition of somatic cells requires an extensive reprogramming of the cell transcriptome. Relevantly, the extensive modulation of the genes that have a regulatory function, in particular the genes encoding the transcription factors (TFs) and miRNAs, have been indicated as controlling somatic embryogenesis (SE) that is induced in vitro in the somatic cells of plants. Identifying the regulatory relationships between the TFs and miRNAs during SE induction is of central importance for understanding the complex regulatory interplay that fine-tunes a cell transcriptome during the embryogenic transition. Hence, here, we analysed the regulatory relationships between AGL15 (AGAMOUS-LIKE 15) TF and miR156 in an embryogenic culture of Arabidopsis. Both AGL15 and miR156 control SE induction and AGL15 has been reported to target the MIR156 genes in planta. The results showed that AGL15 contributes to the regulation of miR156 in an embryogenic culture at two levels that involve the activation of the MIR156 transcription and the containment of the abundance of mature miR156 by repressing the miRNA biogenesis genes DCL1 (DICER-LIKE1), SERRATE and HEN1 (HUA-ENHANCER1). To repress the miRNA biogenesis genes AGL15 seems to co-operate with the TOPLESS co-repressors (TPL and TPR1-4), which are components of the SIN3/HDAC silencing complex. The impact of TSA (trichostatin A), an inhibitor of the HDAC histone deacetylases, on the expression of the miRNA biogenesis genes together with the ChIP results implies that histone deacetylation is involved in the AGL15-mediated repression of miRNA processing. The results indicate that HDAC6 and HDAC19 histone deacetylases might co-operate with AGL15 in silencing the complex that controls the abundance of miR156 during embryogenic induction. This study provides new evidence about the histone acetylation-mediated control of the miRNA pathways during the embryogenic reprogramming of plant somatic cells and the essential role of AGL15 in this regulatory mechanism.
\end{abstract}

Keywords: somatic embryogenesis; AGL15; miR156; miRNA biogenesis; acetylation; HDAC; TOPLESS co-repressor; HEN1; SERRATE; DCL1

\section{Introduction}

The molecular mechanisms that underlie the phenomenon of the toti-/pluripotency of somatic cells remain at the centre of developmental biology. In plants, insights into somatic embryogenesis (SE) that is induced in in vitro-cultured explants contribute to identifying the regulatory processes that control the embryogenic reprogramming of somatic cells. Transcription factors (TFs) and miRNAs play a central role in the response of a somatic cell transcriptome to the SE-inducing factors such as 
auxin treatment [1-4]. Hence, identifying the regulatory relationships between the TFs and miRNAs is of central importance for understanding the complex network that fine tunes the transcriptomes of the somatic cells during the induction of SE.

The SE-involved genes encode numerous TFs that have hormone- and stress-related functions [5-9] and among them, AGAMOUS-LIKE15 (AGL15) of the MADS-box family of TFs has been identified [10,11]. AGL15 encodes the MADS-domain protein that selectively binds to a consensus DNA sequence, the CArG (C-A/T rich-G) motif, in order to either activate or repress the expression of the target genes [12]. The binding of AGL15 to numerous hormone-related loci in the Arabidopsis genome implies that AGL15 controls embryogenic induction by regulating gibberellic acid and ethylene metabolism and auxin signalling $[13,14]$. Accordingly, AGL15 directly targets the GIBBERELLIN 2-OXIDASE2, GIBBERELLIC ACID INSENSITIVE, and ACC SYNTHASE, ACC OXIDASE genes that regulate the metabolism of gibberellic acid and ethylene, respectively [15-17]. Accordingly, AGL15 might positively affect SE induction by directly activating GA 2-oxidase, which results in a decreased level of biologically active GA [10]. AGL15 also affects auxin signalling as a result of the repression of the TRANSPORT INHIBITOR RESPONSE 1, AUXIN RESPONSE FACTOR 6 and IAA30 genes [14]. In addition to directly regulating the hormone-related genes AGL15 also indirectly affects hormone metabolism and signalling via regulatory interactions with other TFs that have been indicated as having essential functions in SE, including LEAFY COTYLEDON2, FUSCA3 and BABY BOOM (reviewed in [18-20]).

In addition to protein-encoded genes, the MIR genes encoding microRNA (miRNAs) $[13,21]$ are also targets of AGL15. miRNAs, which are small (19-24 nucleotide long), single-stranded non-coding RNA molecules, regulate both the state of the chromatin which is associated with target genes and the availability of the encoded transcripts for protein translation [22]. In the control of plant development, miRNAs preferentially target the genes that have a regulatory function including those encoding the TFs $[23,24]$.

The differential expression of numerous miRNAs, mostly hormone-related, has been attributed to SE induction in different plants including Arabidopsis [25-30]. Auxin-related functions during SE induction have been demonstrated for miR393, miR396, miR160 and miR167, which have an auxin-related function [31-33]. An analysis of the expression of different MIRs in embryogenic cultures of Arabidopsis and other plants has indicated highly diverse expression patterns between the members of the same MIR gene family [27,30,34-36]. Therefore, the extensive transcriptional regulation of different $M I R$ genes seems to contribute to the production of functional miRNA molecules during SE induction. Although the MIR promoters, similar to the protein-coding genes might be activated or repressed by the binding of specific regulatory proteins, only a few TFs that target specific MIR genes have been identified to date [37].

The contribution of AGL15 to the positive regulation of the MIR156 genes has been reported during flower development [21]. Importantly, MIR156 genes were reported to be among the potential targets of AGL15 in an embryogenic culture [13] and consequently, the regulatory functions of miR156 in SE induction in different plants have been postulated (reviewed in [1,4]). Moreover, the accumulation of both AGL15 and miR156 transcripts in the cotyledons of Arabidopsis that contribute to SE induction in this plant has been demonstrated [21,38]. Taken together, these findings suggest that AGL15 might control miR156 during SE induction.

The regulatory mechanism by which AGL15 might control the target genes involves interactions with the SIN3/HDAC (Swi-independent3/Histone Deacetylase) silencing complex [39]. By recruiting the TOPLESS (TPL) and TPL-RELATED (TPR) transcriptional corepressors [40], AGL15 directs the histone deacetylases (HDACs) to the target gene loci [41]. The HDACs that operate in the SIN3/HDAC silencing complex include HDAC19 and HDAC6 of the Reduced Potassium Dependence 3/Histonee Deacetylase 1 family of histone deacetylases whose members play a critical role in various development processes and stress responses (reviewed in [42]). The function of HDAC6 and HDAC19 in controlling the embryogenesis-related genes during zygotic embryogenesis has been documented including the HDAC19-mediated repression of LEC1 and LEC2 genes, which are the master regulators of both 
zygotic and somatic embryogenesis [20,43-45]. Relevantly, although HDAC6 and HDAC19 have been postulated to function in the histone acetylation-mediated control of SE, the target genes remain to be revealed $[40,42,46,47]$.

Here, in order to verify the assumption about the regulatory relationship of AGL15 and the abundance of miR156 in SE, we analysed the impact of AGL15 on both the transcription of the MIR156 genes and the level of mature miR156 molecules in an embryogenic culture of Arabidopsis. Insights into the gene expression profiles in different mutants and transgenic lines together with the results of the ChIP analysis indicated that AGL15 contributes to the regulation of miR156 in an embryogenic culture at two levels that involve the activation of MIR156 transcription and the containment of the abundance of mature miR156 by repressing the miRNA biogenesis genes DCL1, SERRATE, and HEN1. We also showed that to repress the miRNA biogenesis genes AGL15 seems to co-operate with other components of the SIN3/HDAC silencing complex including the TOPLESS co-repressors and HDAC6 and HDAC19 histone deacetylases. The study provides new evidence about the histone acetylation-mediated control of the miRNA pathways during the embryogenic reprogramming of plant somatic cells and the essential role of AGL15 in this regulatory mechanism.

\section{Results}

\subsection{AGL15 Impacts the Abundance of Mature miR156}

The role of AGL15 in the activation of two MIR156 genes (MIR156a and c) during flowering [21] motivated us to gain insights into the regulatory relationship between AGL15 and miR156 in SE induction. To this end, the abundance of the primary miR156 transcripts (pri-miR156) of eight MIR156 $(M I R 156 a-h)$ genes that are present in the Arabidopsis genome was analysed in cultures that had different AGL15 expression levels, including WT (Col-0), 35S::AGL15, and agl15 agl18. The results showed that there was no relationship between the AGL15 expression level and the transcription of seven of the MIR156 genes (MIR156a-g) and that both the overexpression (35S::AGL15) and knock-out mutation (agl15 agl18) resulted in a significant increase in pri-miR156a-g (Figure 1). By contrast, pri-miR156h had a high (up to 15-fold) up-regulation in response to the overexpression of AGL15 and a distinct downregulation (up to two-fold) in the agl15agl18 mutant culture, which suggests that AGL15 might positively regulate MIR156h during SE induction.

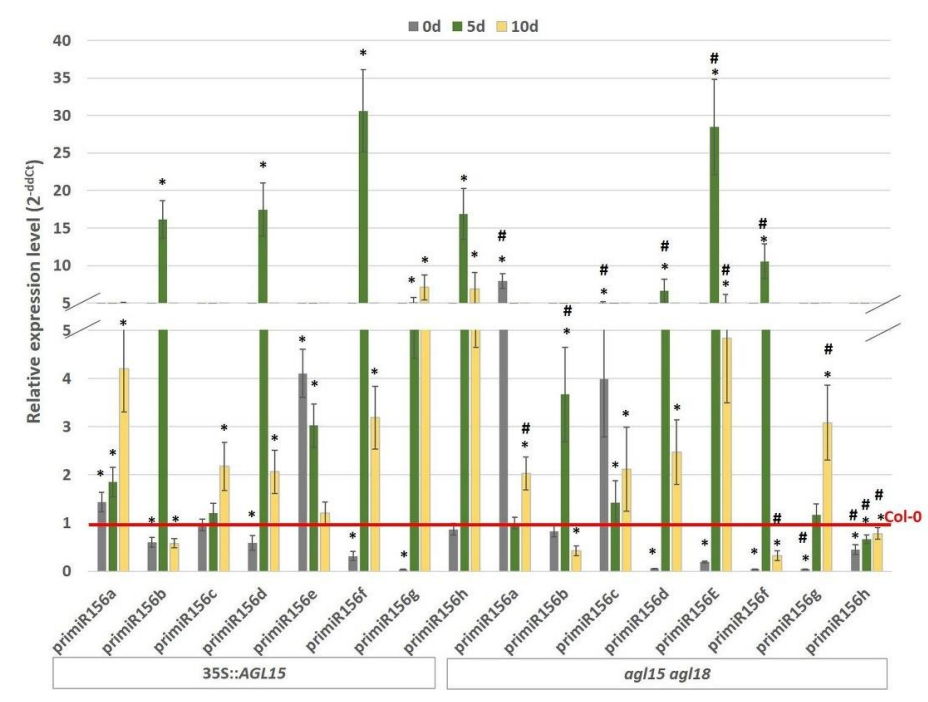

Figure 1. Relative expression level of pri-miR156s in the embryogenic cultures of the 35S::AGL15 and agl15 agl18 transgenic lines. The relative miRNA level was normalised to an internal control (At4g27090) and calibrated to a Col-0 culture of the same age. * value significantly different from the Col-0 culture of the same age $(p<0.05 ; n=3 \pm \mathrm{SD}) ;{ }^{*}$ value significantly different from the 35S::AGL15 culture of the same age $(p<0.05 ; n=3 \pm \mathrm{SD})$. 
To learn more about the role of AGL15 in regulating miR156 during embryogenic induction, we analysed the accumulation of mature miR156 compared to the AGL15 expression level. Unexpectedly, the results showed that AGL15 significantly modulated the abundance of mature miR156 and that there was a distinctly higher (from 2- to 14-fold) abundance of mature miR156 in the agl15 agl18 mutant than in the 35S::AGL15 culture (Figure 2). The results suggest a repressive function of AGL15 in the processing of miR156 molecules that precedes the production of functional miR156 molecules during the embryogenic reprogramming of a somatic cell.

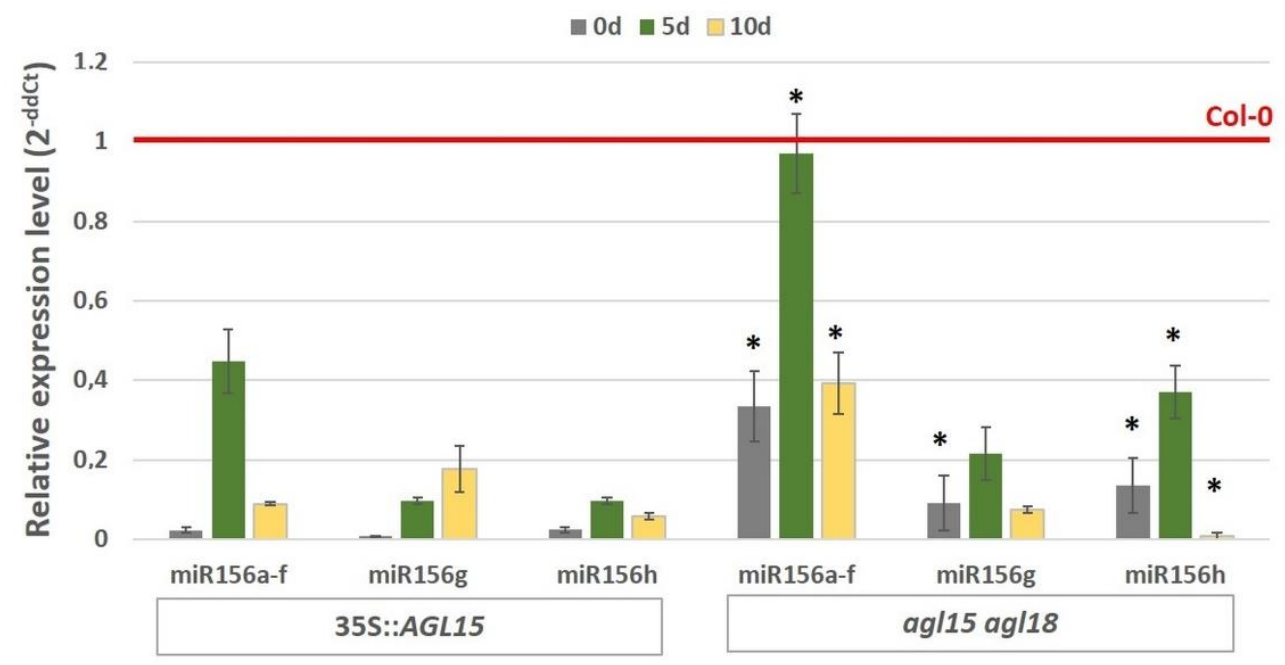

Figure 2. Abundance of mature miR156s in the embryogenic cultures of the 35S::AGL15 and agl15 agl18 transgenic lines. The relative miRNA level was normalised to an internal control (At4g27090) and calibrated to the Col-0 culture of the same age. ${ }^{*}$ value significantly different from the 35S::AGL15 culture of the same age $(p<0.05 ; n=3 \pm \mathrm{SD})$.

\subsection{AGL15 Negatively Controls the Expression of the miRNA Biogenesis Genes during Embryogenic Induction}

The post-transcriptional mechanism that extensively fine tunes the mature miRNA level via miRNA-processing machinery has been assumed in an embryogenic culture [30]. Thus, we hypothesised that AGL15 might interact with the components of the miRNA biogenesis pathway to control the production of the functional mature miR156 during SE induction. To verify this assumption, we determined that it was reasonable to assess the regulatory relationships between AGL15 and the genes encoding the critical components of miRNA biogenesis genes including DICER-LIKE1 (DCL1), SERRATE, HUA-ENHANCER1 (HEN1) and HYPONASTIC LEAVES1 (HYL1). To this end, the expression of these genes relative to the AGL15 expression level was evaluated in embryogenic cultures of the 35S::AGL15 and agl15 agl18 double-mutant lines. The analysis indicated a significant decrease (2- to more than 3000-fold) in the DCL1, SERRATE, HEN1 and HYL1 expression in the SE culture that overexpressed AGL15 (Figure 3A) and the upregulation of DCL1, SERRATE, HEN1 in the culture of the agl15 agl18 mutant (Figure 3B). By contrast, the expression of HYL1 was downregulated in the both 35S::AGL15 and agl15 agl18 cultures compared to WT (Col-0), which implies a lack of any regulatory impact of AGL15 on HYL1. In summary, the results suggest that AGL15 may negatively affect the expression of three of the miRNA biogenesis genes including DCL1, HEN1, and SERRATE. 

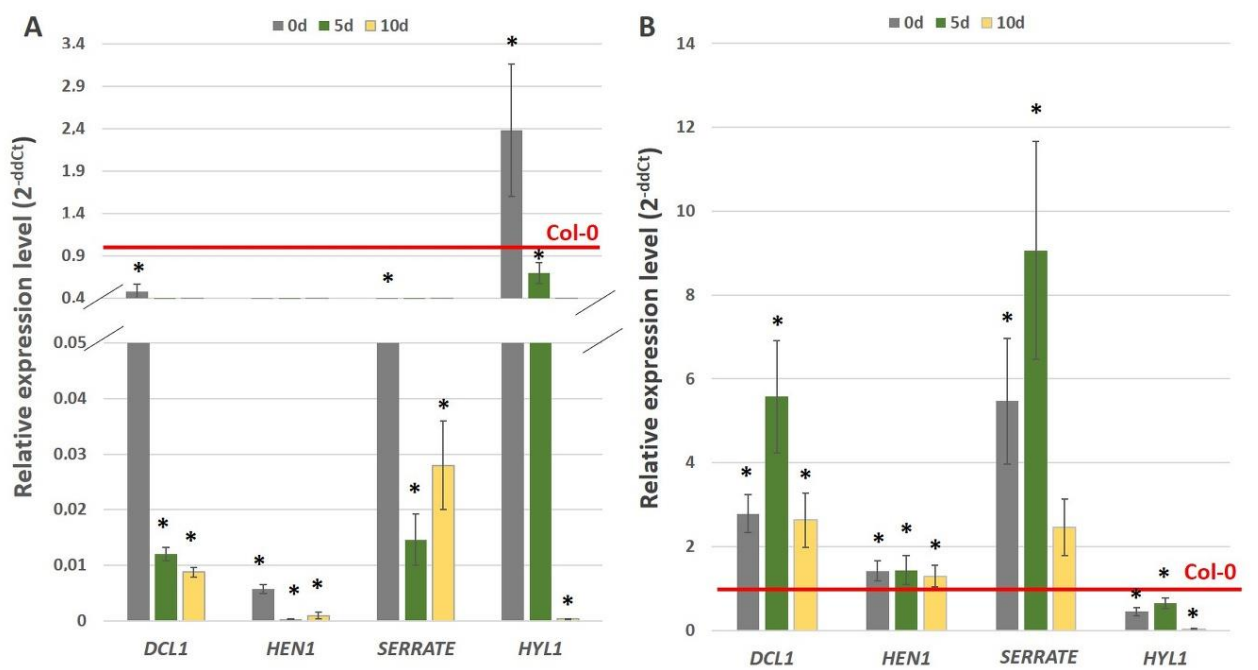

Figure 3. Relative expression level of the miRNA biogenesis genes (DCL1, HEN1, SERRATE and HYL1) in the embryogenic cultures of the 35S::AGL15 (A) and agl15 agl18 (B) transgenic lines. The relative expression level was normalised to an internal control (At4g27090) and calibrated to the Col-0 culture of the same age. * value significantly different from the Col- 0 culture of the same age $(p<0.05 ; n=3 \pm \mathrm{SD})$.

2.3. Histone Acetylation Might Be Involved in the AGL15-Mediated Control of the miRNA Biogenesis Genes in SE Induction

The possible mechanisms that are involved in the AGL15-mediated repression of the target genes might include the interaction of AGL15 with a SIN3/HDAC silencing complex by the histone deacetylases, HDACs [48]. Therefore, we hypothesised that AGL15 acts as a repressor of the miRNA biogenesis genes (DCL1, HEN1, and SERRATE) in embryogenic culture via its interaction with the HDACs. To verify this hypothesis, we evaluated the effect of the HDAC inhibitor, trichostatin A (TSA), on the DCL1, SERRATE, and HEN1 gene expression in the 35S::AGL15 and agl15 agl18 mutant cultures. We found that there was a significant up-regulation (from 2- to 120-fold) of the DCL1, SERRATE and HEN1 genes in the culture that was overexpressing AGL15 and a distinctly smaller increase of the gene transcripts in the mutant culture (Figure 4). This result supported the assumption of the role of histone acetylation in the AGL15-mediated control of the miRNA biogenesis gene expression during SE induction.
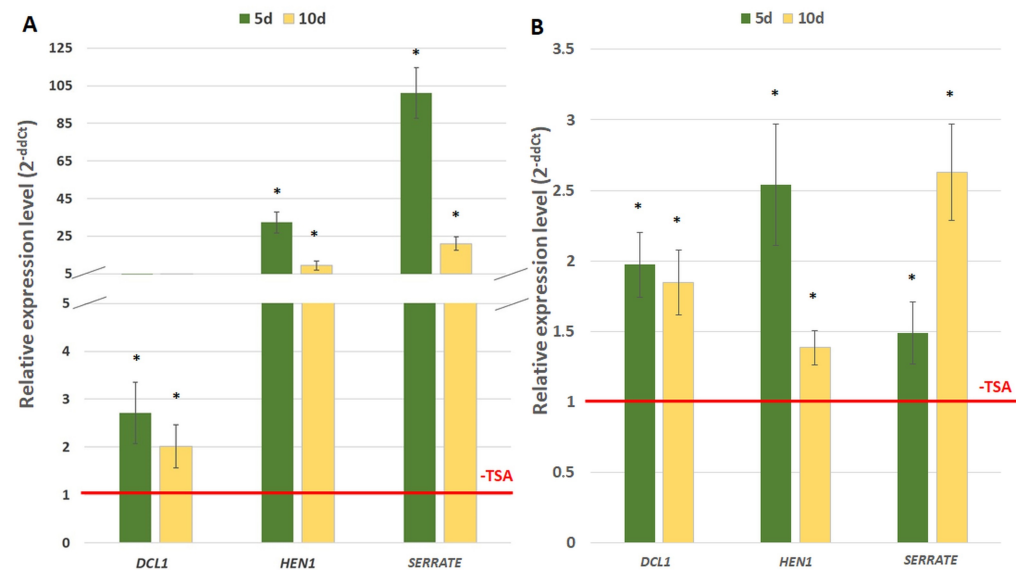

Figure 4. Relative expression level of the miRNA biogenesis genes (DCL1, HEN1, SERRATE) in the embryogenic cultures of the 35S::AGL15 (A) and agl15 agl18 (B) transgenic lines that had been treated with a TSA (Trichostatin A). The relative expression level was normalised to an internal control (At4g27090) and calibrated to the untreated culture of the genotypes of the same age. ${ }^{*}$ value significantly different from the culture of the same age untreated with a TSA $(p<0.05 ; n=3 \pm$ SD). 
Next, we examined whether the histone deacetylases HDAC6 and HDAC19, which have a regulatory interaction with the AGL15 protein [48], might contribute to the AGL15-mediated control of the miRNA biogenesis genes in an embryogenic culture. Relevantly, we found that the HDAC6 and HDAC19 genes were downregulated in the embryogenic culture (Figure 5A) and that the mutants that were defective in these genes ( $h d a c 6$ and $h d a c 6 / h d a c 19$ ) had a significantly impaired embryogenic response (Figure 5B,C). These results implied a role of HDAC6 and HDAC19 in SE induction. Next, to verify whether HDAC6 and HDAC19 might control embryogenic induction via the regulation of miRNA biogenesis genes, we analysed the expression of DCL1, HEN1, and SERRATE in the embryogenic culture of $h d a c 6$ and $h d a c 6$ hdac19 mutants. The analysis indicated that the impaired expression of HDAC6/19 in the mutants resulted in an increase in the expression of DCL1, HEN1, and SERRATE during somatic embryogenesis (Figure 6). The results provide support for the role of HDAC6/19 in the histone acetylation-mediated control of miRNA biogenesis during embryogenic induction.
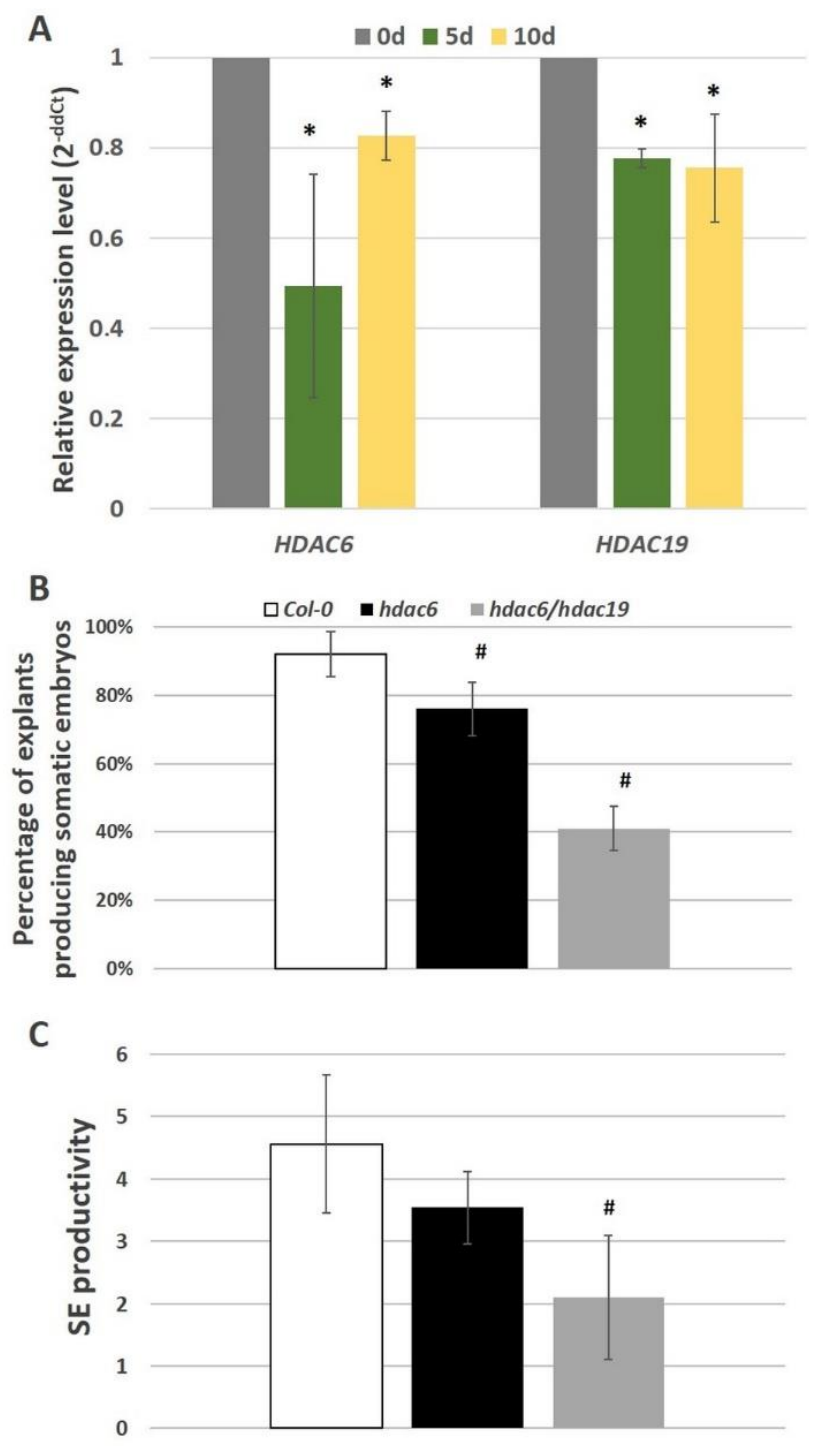

Figure 5. Expression analysis of HDAC6 and HDAC19 (A) in the SE culture of the Col-0 genotype. Capacity for SE in the cultures of the hdac6 and hdac6 hdac19 mutants and their parental genotype, Col-0. Percentage of explants producing somatic embryos (B) and SE productivity (C) of the IZE explant culture that was induced on an E5 medium. The relative transcript level was normalised to an internal control (At4g27090) and calibrated to freshly isolated explants (0d). * value significantly different from the freshly isolated explants (0d) $(p<0.05 ; n=3 \pm \mathrm{SD})$; ${ }^{\#}$ values significantly different from the Col-0 $(p<0.05 ; n=3 \pm \mathrm{SD})$. 


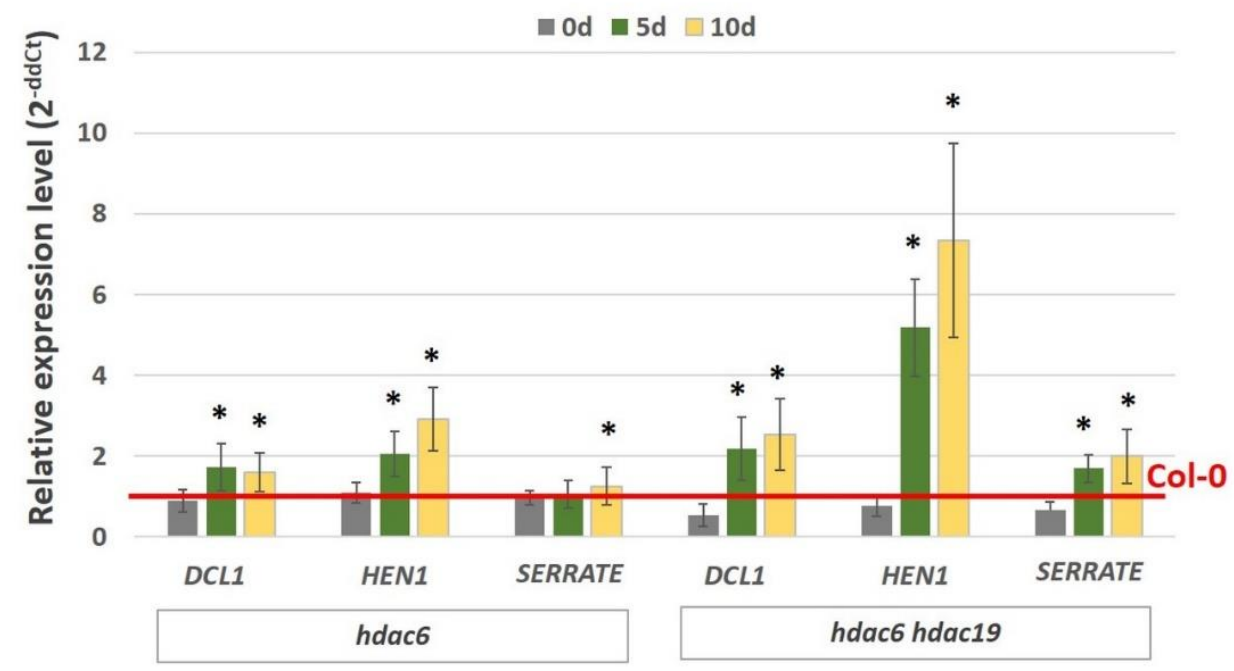

Figure 6. Relative expression of the miRNA biogenesis genes (DCL1, HEN1, SERRATE) in the SE cultures of the $h d a c 6$ and $h d a c 6$ hdac19 mutant lines. The relative transcript level was normalised to an internal control (At4g27090) and calibrated to the Col-0 culture of the same age. * values significantly different from the Col- 0 culture of the same age $(p<0.05 ; n=3 \pm \mathrm{SD})$.

2.4. AGL15 Impacts the Acetylation Level of Histone H3, Which Is Associated with the Promoter of the DCL1 and SERRATE Genes in an Embryogenic Culture

The results suggest that in an embryogenic culture, AGL15 might repress the expression of the miRNA biogenesis genes DCL1, HEN1 and SERRATE, via histone deacetylation. To confirm this assumption, we examined the histone acetylation in the chromatin that is associated with the promoters of the miRNA biogenesis genes during embryogenic induction. The H3K9 and K14 positions, which have a positive influence on gene expression $[49,50]$ were analysed. Most of the AGL15-bound sites are located within $1 \mathrm{~kb}$ of the transcription unit of the target gene and carry at least one CArG motif [13]. It was observed that the fragments of DCL1, SERRATE and HEN1 promoters that were analysed using ChIP were located upstream ( $-600 \mathrm{bp}$ or $-400 \mathrm{bp})$ and downstream (+300 bp) to TSS and included one to six CArG sequences (Supplementary Figure S1). ChIP analysis using the anti-H3K9/14ac antibody was performed and the different promoter regions that include the TSS +300 and CArG sequences were examined in the explants of the 35S::AGL15 and agl15 agl18 transgenic lines that had been induced for five days on an SE-induction medium.

The analysis revealed AGL15-dependent changes in $\mathrm{H} 3$ acetylation in the chromatin which is associated with the analysed regulatory fragments (fragment 1 and TSS + 300) of two genes DCL1 and SERRATE (Figure 7). The acetylation level of histone $\mathrm{H} 3$ associated with these genes was substantially increased and decreased in the agl15 agl18 mutant and the AGL15 overexpression line cultures, respectively. In conclusion, AGL15 might negatively control the miRNA biogenesis genes DCL1 and SERRATE during SE induction via histone acetylation-related mechanisms in which HDAC6 and HDAC19 seem to operate. 

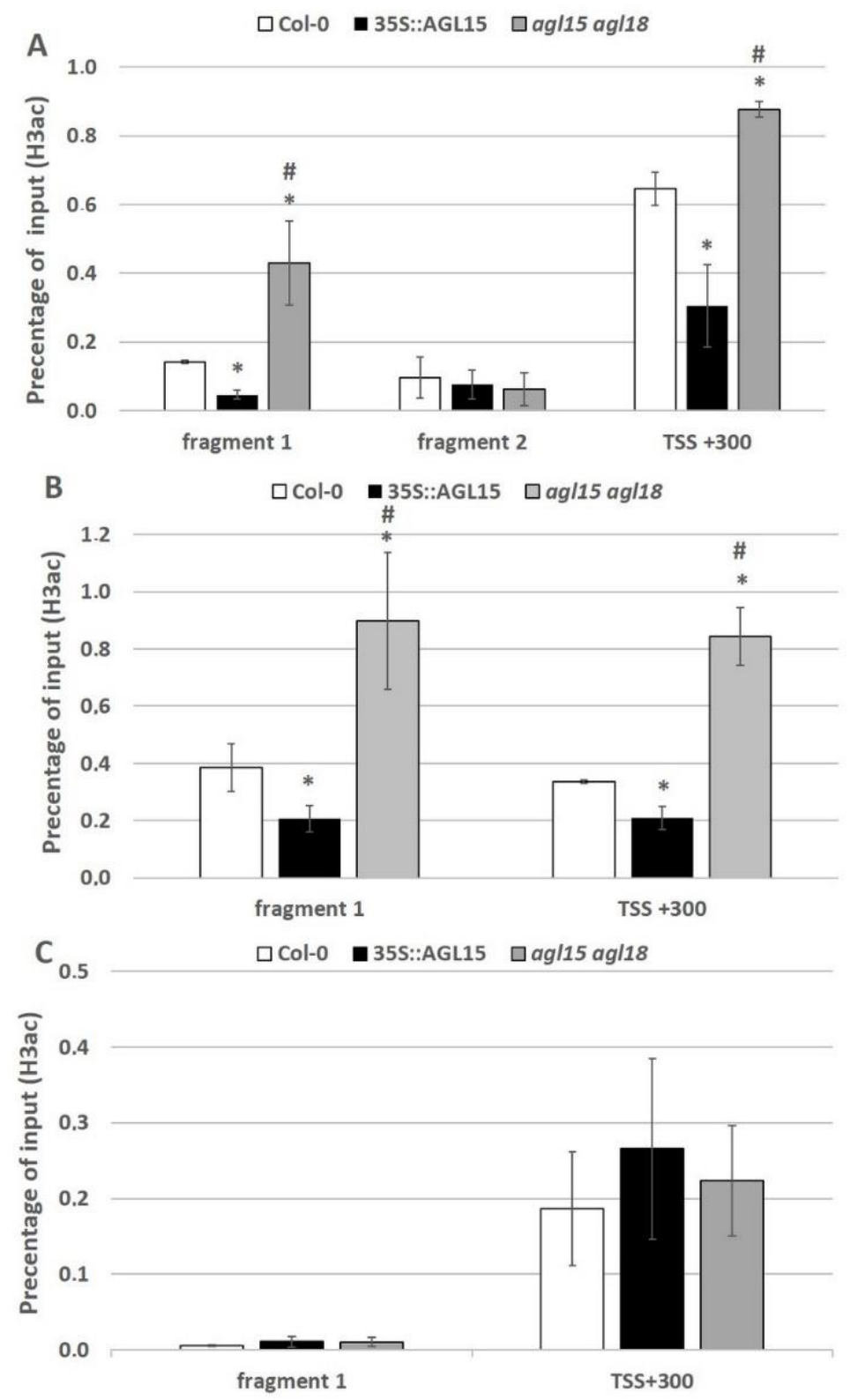

Figure 7. H3ac enrichment in a selected fragment of a promoter and TSS +300 of the DCL1 (A), SERRATE (B) and HEN1 (C) genes in the explants of the Col-0, 35S::AGL15 and agl15 agl18 lines. * value significantly different from the Col-0 $(p<0.05 ; n=3 \pm \mathrm{SD})$; ${ }^{\#}$ value significantly different from the 35S::AGL15 $(p<0.05 ; n=3 \pm \mathrm{SD})$.

2.5. TPL Co-Repressors Might Contribute to the AGL15-Mediated Control of the miRNA Biogenesis Genes in an Embryogenic Culture

To identify any other elements of the AGL15-related complex that silence the expression of the miRNA biogenesis genes in somatic embryogenesis, we investigated the possible involvement of the TOPLESS (TPL) co-repressors, which directly interact with AGL15 [39]. The expression profiling of the TPL and four TPR (TPR1-4) genes indicated that they were significantly down-regulated during embryogenic induction (Figure 8A). Together with the severely impaired embryogenic potential of the tpl, tpr1, and tpr4 mutant culture (Figure $8 \mathrm{~B}, \mathrm{C}$ ), the results suggest a role of the TPL/TPR co-repressors (TPL, TPR1, TPR4) in somatic embryogenesis induction. 

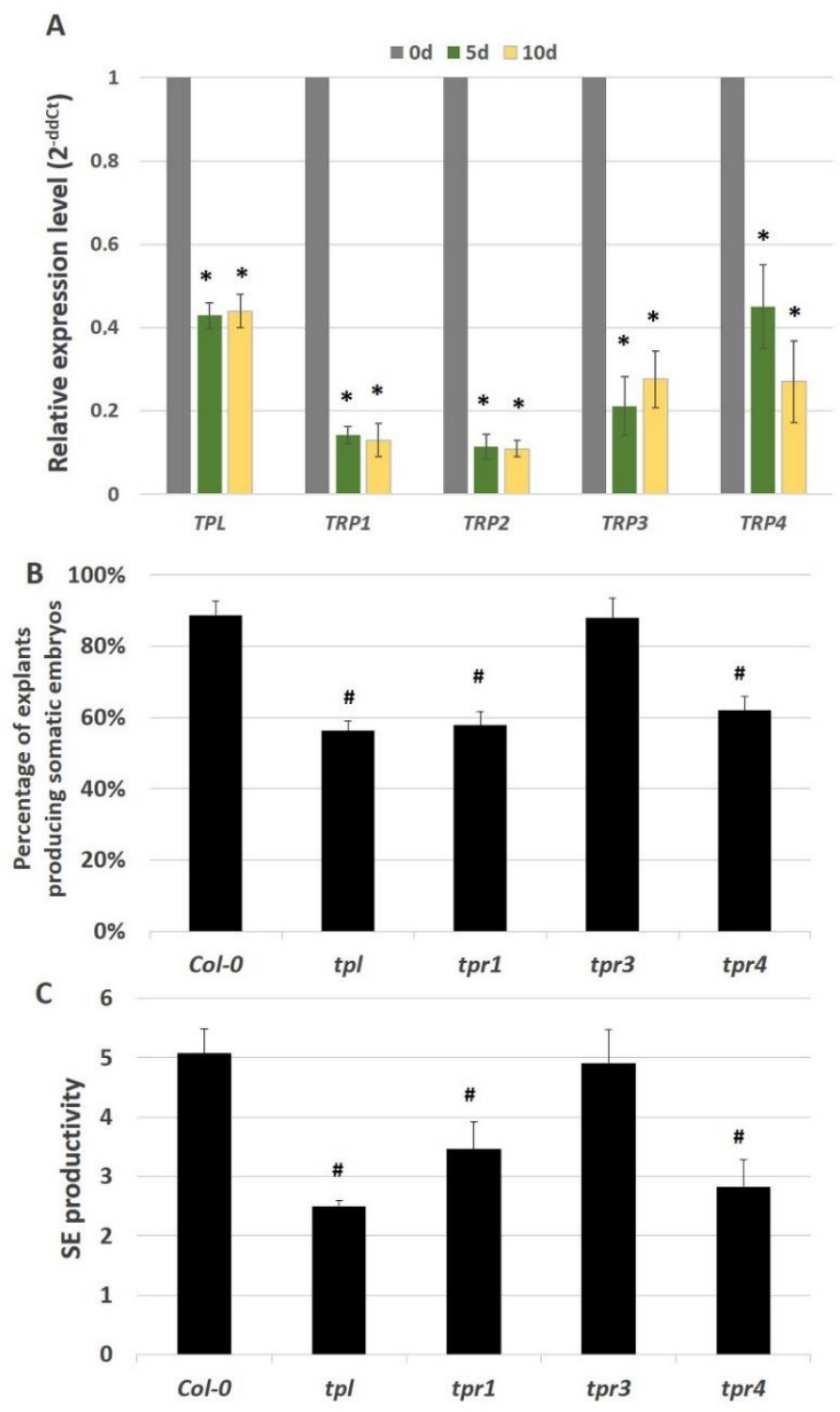

Figure 8. Relative expression level of the genes encoding the TOPLESS co-repressors (TPL, TPR1-4) in the embryogenic culture of Col-0 (A). Capacity for somatic embryogenesis in the cultures of mutants in the TOPLESS co-repressor genes (tpl, tpr1, 3, 4) and their parental genotype, Col-0. Percentage of explants producing somatic embryos $(\mathbf{B})$ and SE productivity $(\mathbf{C})$ of the IZE explant culture that was induced on an E5 medium. The relative expression level was normalised to an internal control (At4g27090) and calibrated to freshly isolated explants (0d). ${ }^{*}$ value significantly different from the freshly isolated explants (0d) $(p<0.05 ; n=3 \pm \mathrm{SD})$; ${ }^{\#}$ values significantly different from Col- $0(p<0.05$; $n=3 \pm \mathrm{SD})$.

Next, we assumed that the TPLs might impact the miRNA biogenesis genes in an embryogenic culture and the expression of DCL1, HEN1, and SERRATE in the tpl, tpr1 and tpr4 mutants was analysed in order to verify this hypothesis. The analysis showed that two of the miRNA biogenesis-related genes DCL1 and SERRATE, were significantly up-regulated in the embryogenic-induced explants of all three (tpl, tpr1, and tpr4) mutants (Figure 9). By contrast, there was a substantial increase of the HEN1 transcripts exclusively in the tpr4 mutant culture, which suggests that different TPL co-repressors might be involved in the control of distinct miRNA biogenesis genes in an embryogenic culture. 


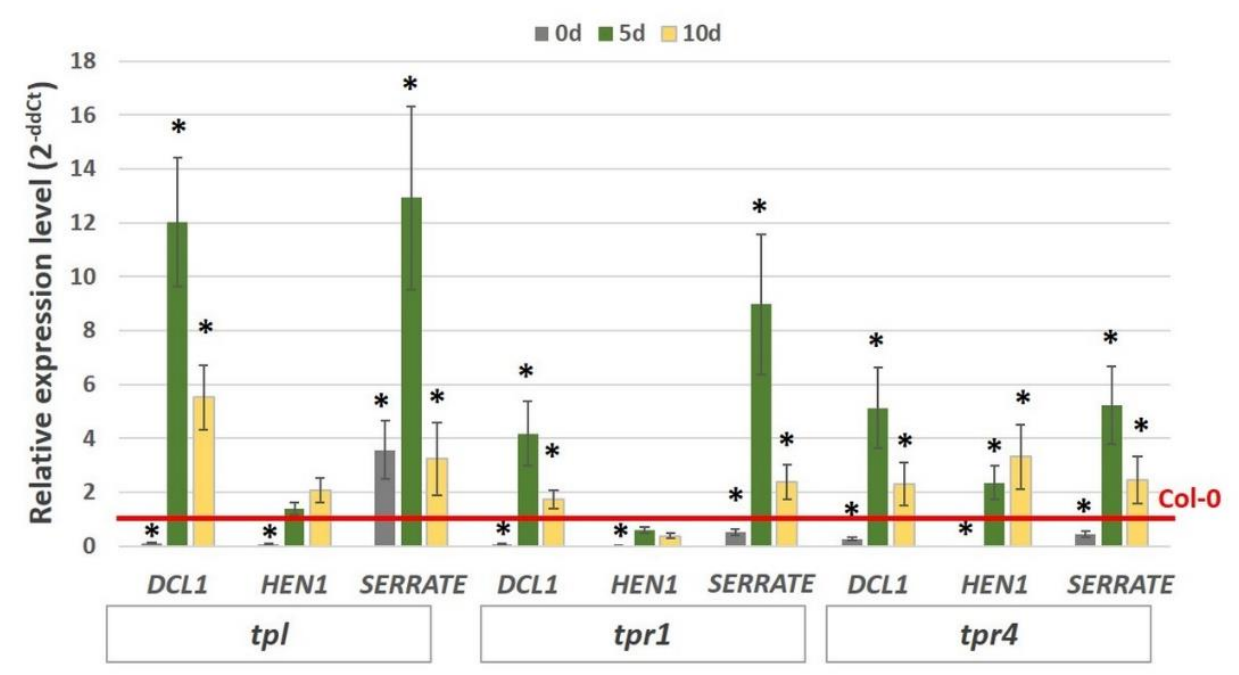

Figure 9. Relative expression of the miRNA biogenesis genes (DCL1, HEN1, SERRATE) in the embryogenic culture of the TOPLESS co-repressor mutants (tpl,tpr1, tpr4). The relative transcript level was normalised to an internal control (At4g27090) and calibrated to the Col-0 culture of the same age.

* values significantly different from the Col-0 culture of the same age $(p<0.05 ; n=3 \pm \mathrm{SD})$.

Taken together, the results showed that the TPL co-repressors might contribute to the AGL15-mediated negative control of the miRNA-biogenesis genes. Accordingly, AGL15 seems to cooperate with TPL, TPR1, and TPR to silence the DCL1 and SERRATE genes while the cooperative interaction between AGL15 and TRP4 is assumed to repress HEN1 during embryogenic induction.

\section{Discussion}

\subsection{AGL15 Controls miR156 by Activating MIR156h Transcription during Embryogenic Induction}

The presented transcript analysis of eight MIR156 $(a-h)$ genes in embryogenic cultures with different levels of AGL15 expression (agl15 agl18 vs. 35::AGL15) suggested that AGL15 might positively regulate the MIR156h expression during SE induction (Figure 1). Interestingly, MIR156h has also been indicated as being among the stress-regulated MIR genes [51] and the involvement of AGL15 in the regulation of stress-related genes has also been reported [52]. Therefore, we assumed that the activation of MIR156h by AGL15 during SE induction might be caused by the stress that is imposed by in vitro culture conditions including 2,4-D treatment [53]. In flower development, two other MIR156 genes MIR156 $a$ and MIR156c, were directly activated by AGL15 [21] and together these findings imply that AGL15 might target different MIR156 genes depending on the developmental process. Besides AGL15, other TFs have been reported to control individual MIR156 genes including the involvement of FUS3 TF that activates MIR156 $a$ and MIR156c in seed development [54] and APETALA 2 TF that positively regulates MIR156e during flower development [55]. Whether these TFs, in particular FUS3, which have a substantial impact on embryogenic induction [43], might control the MIR156 genes in an embryogenic culture remains to be explored.

The complexity of the TF-regulatory network that controls the MIR156 gene expression has clearly been demonstrated in flower development. This network involves the direct activation of different MIR156 genes by AP2 and AGL15 and the positive and direct regulation of AGL15 by miR156-controlled AP2 [21,55]. The extensive regulatory interactions of AGL15 with different proteins, in particular, with other MADS proteins, such as AGL18, AGL24, and SHORT VEGETATIVE PHASE in the transcriptional control of the target genes have been demonstrated [13,21,56]. A number of MADS genes including AGL18, AGL24, SVP and AP2, which are differentially regulated in an embryogenic culture of Arabidopsis ([8,57]) provide candidates that can be used in the search for the proteins that cooperate with AGL15 in the transcriptional regulation of MIR156h in SE induction. 
3.2. AGL15 Together with the TPL/TPR Corepressors Transcriptionally Repress the miRNA Biogenesis Genes DCL1, SERRATE and HEN1 during Embryogenic Induction

In addition to the transcriptional regulation, extensive posttranscriptional processing controls the activity of miRNA [58]. The complex and multi-layered regulation of the miRNA pathways results in frequent inconsistencies in the level of the pri- and mature miRNAs during plant development [37,51,59-61]. Similarly, the robust transcription of numerous MIR genes including MIR156s was associated with distinctly confined accumulation of the relevant mature miRNAs in an embryogenic culture of Arabidopsis [30].

The present results revealed that AGL15 is involved in the control of miR156 at different regulatory levels. In addition to regulating the pri-miR156 level, AGL15 was found to impact the production of mature miR156 in an embryogenic culture. Accordingly, AGL15 negatively affected the abundance of the mature miR156 that was produced by the different MIR156 genes (Figure 2), which suggests a repressive role of AGL15 in the regulatory pathway that controls miR156 processing. The essential role of miRNA biogenesis genes in controlling embryogenic induction has also been demonstrated [31] and the DCL1 gene, which has a central function in miRNA biogenesis, has been reported to be among the direct targets of AGL15 in an embryogenic culture of Arabidopsis [13]. In support of the involvement of AGL15 in miRNA processing, we found that AGL15 negatively affected the transcript level of DCL1 and two other genes that are involved in miRNA biogenesis, SERRATE, and HEN1 (Figure 3).

Complex and multi-layered regulatory interactions have been demonstrated to fine tune the components of the miRNA processing pathways [37,58,62]. However, our knowledge of the regulatory network that controls miRNAs remains incomplete and, in particular, the TFs that regulate the miRNA biogenesis genes in different tissues as well as the developmental processes need to be identified $[37,58,62]$. The present results indicated that AGL15 is a regulator of miRNA during the embryogenic transition that is induced in vitro in Arabidopsis. The study provides some evidence that AGL15 may control the miR156 activity by positively regulating the abundance of the pri-miR156 transcript and the negative control of the genes encoding crucial components of pri-miRNA biogenesis (DCL1, SERRATE and HEN1).

We hypothesised that the repressive function of AGL15 in miRNA biogenesis might also involve other miRNAs and in support of this, we found a substantially higher level of the mature miR167 and miR172 transcripts in the culture of the agl15 agl18 mutant than in the 35S::AGL15 line (Supplementary Figure S2). The role of AGL15 in the transcriptional regulation of miR172 has also been documented during flower development [21,55] and AGL15 has been shown to directly control the MIR167 (MIR167a) expression in an embryogenic culture [52]. Importantly, a common histone acetylation-related mechanism controls the miR156, miR167 and miR172 biogenesis in Arabidopsis seedlings [63]. Hence, we postulate that similar to miR156, AGL15 might also repress miR167 and miR172 during SE, through an interaction with the histone deacetylases silencing complex. Further analysis is required to verify this hypothesis.

The results also imply that the AGL15 repression of the miRNA biogenesis genes in an embryogenic culture may involve the TPL/TPR co-repressors. Similarly, AGL15 in cooperation with TPL/TPR controls the genes that are involved in flowering [39]. An analysis of the embryogenic response of the tpl/tpr mutants (Figure 8) indicated that three of the corepressors, TPL, TPR2 and TPR4, control SE induction. Two of the SE-involved corepressors, TPL and TPR2, may directly interact with AGL15 through the TOPLESS domain, which has a binding affinity to the EAR domain that is present in numerous transcriptional repressors including AGL15 [39,64].

The results imply that different TPL/TPR proteins might control the different miRNA biogenesis genes during SE induction (Figure 9). Accordingly, TPL, TPR2 and TPR4 acting together seem to regulate the DCL1 and SERRATE expression, while TPR4 alone may be involved in the repression of HEN1. The gene silencing complexes commonly consist of different TPL/TPR proteins $[65,66]$. However, recently, a monomeric form of TPL was found to be sufficient to cause an intense transcriptional 
repression in plants [67]. This finding supports our assumption that different TPL/TPR complexes, both composed and monomeric, might control the different miRNA biogenesis genes.

Besides cooperating with AGL15 to control the miRNA biogenesis genes other divergent and multiple roles of the TPL/TPR corepressors in SE induction might be expected because the TOPLESS proteins cooperate with a variety of TF families [39]. The representatives of these TF families, including WUS/WOXs, ARFs, AUX/IAA, and BBM, have an essential regulatory function during embryogenic induction [68-73]. Moreover, the essential function of TPL/TPRs in regulating the hormone (auxin)-responses including those that control the apical embryonic fate in zygotic embryos was found $[40,64,74]$. Thus, the versatile but as yet unknown regulatory functions of TPL/TPR in regulating the SE-transcriptome might be assumed and the contribution of these corepressors to the AGL15-controlled miRNA biogenesis seems to be one of them.

\subsection{The AGL15-Mediated Repression of the miRNA Biogenesis Genes Involves Histone Deacetylation}

The gene-repressive function of AGL15 involves the modulation of histone acetylation and a transcriptional repression motif in AGL15 recruits the histone deacetylase SIN3/HDAC complex components in order to repress the target genes $[39,48]$. We hypothesized that similar histone acetylation-related mechanisms operate during the AGL15-mediated repression of the miRNA biogenesis genes during embryogenic induction. In support of this assumption, we found that the repressive effect of AGL15 on the DCL1, HEN1, and SERRATE genes is modulated by TSA, which is an HDAC inhibitor (Figure 4) and that AGL15 significantly decreased the acetylation level of the H3 histone associated with the DCL1 and SERRATE promoters in the embryogenic culture (Figure 7).

Although, in contrast to DCL1 and SERRATE, the impact of AGL15 on the acetylation of histones in chromatin associated with HEN1 promoter, was not found to be significant (Figure 7), the involvement of histone acetylation in the repression of HEN1 in an embryogenic culture implies an increased expression of this gene in the hdac mutants (Figure 6). We cannot rule out the fact that another CArG motif located farther from TSS (-900 bp) might be involved in the histone acetylation-mediated and AGL15-controlled expression of HEN1. Different (de)acetylases and (de)methylases of histones interplay extensively in the control of gene expression and mutations in HDAC19 may affect both the acetylation and methylation of histones [39,44,75-78]. Thus, histone methylation might contribute to the AGL15-mediated repression of HEN1 and the role of histone methylation in the control miRNA biogenesis genes needs to be investigated in the future.

To learn more about the SIN3/HDAC components that are engaged in the repression of miRNA biogenesis genes during SE induction, we analysed the HDAC6 and HDAC19 deacetylases that have reported interactions with AGL15 [48]. A role of histone deacetylases including HDAC6 and HDAC19 in embryogenic development in Arabidopsis has been suggested $[47,79]$. Relevantly, we indicated that the $h d a c 6$ and $h d a c 6 / h d a c 19$ mutations negatively affected the embryogenic response in the explant culture (Figure 5). In addition, the results offered some indirect clues on the involvement of HDAC6 and HDAC19 in the AGL15-mediated repression of the miRNA biogenesis genes during SE induction. Accordingly, we found that mutations in HDAC6/19 positively affected the level of the DCL1, SERRATE and HEN1 transcripts in the embryogenic culture (Figure 6). Importantly, HDAC19 works in conjunction with TPL to control the transition stage of zygotic embryogenesis [40]. The present results suggest a similar cooperative interaction of HDAC19 with TPL in repressing the miRNA biogenesis genes during embryogenic induction in somatic cells cannot be excluded (Figure 9).

Histone deacetylases interplay with histone acetylases to control gene expression including miRNA biogenesis genes $[42,63,80]$. HAG1/GCN5 histone acetylase contributes to the regulation of DCL1 and HYL1 in seedlings and its essential function in the acquisition of pluripotency in Arabidopsis has been indicated [81]. The role of GCN5 in the histone acetylation-mediated mechanism that controls the miRNAs in an embryogenic culture of Arabidopsis remains to be revealed. 


\section{Materials and Methods}

\subsection{Plant Material and Growth Conditions}

Plants of Arabidopsis thaliana (L.) Heynh. Col-0 (WT) and two transgenic lines with opposite AGL15 (AT5G13790) expression levels were used including the 35S::AGL15 and agl15 agl18 double mutant. In addition, the insertional mutants in the TPL and HDAC genes (tpl-N68599, tpr1-N522964, tpr3-N529936, tpr4-N502209, hdac6 and hdac6 hdac19) were studied. The 35S::AGL15 was kindly provided by Sheryn Perry (University of Kentucky, Lexington, KY, USA), the agl15 agl18 mutant by Donna E. Fernandez (Department of Botany, University of Wisconsin, Madison, WI, USA) and the hdac6 and hdac6 hdac19 by Kim Boutilier (Wageningen University \& Research, Wageningen, Netherlands). The seeds of the other genotypes that were analysed were purchased from NASC (The Nottingham Arabidopsis Stock Centre, Nottingham University, Nottingham, UK). The seeds were sown in 42-mm-diameter Jiffy-7 peat pots (Jiffy) and the plants were grown in a "walk-in" type phytotron under controlled conditions: $22^{\circ} \mathrm{C}, 16 \mathrm{~h} / 8 \mathrm{~h}$ (light/dark) and a light intensity of $100 \mu \mathrm{E} / \mathrm{m}^{2} \mathrm{~s}$. The cultures that were grown in vitro were maintained in a controlled growth chamber at $22^{\circ} \mathrm{C}, 16 \mathrm{~h} / 8 \mathrm{~h}$ (light/dark) and a light intensity of $50 \mu \mathrm{E} / \mathrm{m}^{2} \mathrm{~s}$.

\subsection{Somatic Embryogenesis Induction In Vitro}

Immature zygotic embryos at the late cotyledonary stage were used as the explants for the in vitro cultures according to the standard protocol [82]. The explants were excised from the siliques 10-12 days after pollination, sterilised with sodium hypochlorite ( $20 \%$ commercial bleach) and washed thoroughly with sterile water. The explants were cultured on an E5 solid medium containing B5 salts and vitamins [83] that had been supplemented with $5.0 \mu \mathrm{M}$ 2,4-D (2,4-dichlorophenoxyacetic acid, Sigma, St. Louis, MO, USA), $20 \mathrm{~g} \mathrm{~L}^{-1}$ sucrose and $8 \mathrm{~g} \mathrm{~L}^{-1}$ agar (Oxoid, Hampshire, UK). The explant capacity for SE was evaluated in a three-week-old culture and two parameters were evaluated including SE efficiency, i.e., the percentage of the explants that had formed somatic embryos and SE productivity, i.e., the average number of somatic embryos that had been produced by embryogenic explant.

\subsection{Analysis of the Mature miRNA and Target Gene Expression}

Total RNA was isolated from the explants that had been cultured for 0,5 and $10 \mathrm{~d}$ on the SE-induction E5 medium. In some experiments, the E5 medium was supplemented with $1.0 \mu \mathrm{M}$ of trichostatin A (TSA), which is a blocker of the HDAC activity. RNA was isolated using a miRVana miRNA Isolation Kit. Depending on the age of the culture, $250(0 \mathrm{~d})$ to $50(10 \mathrm{~d})$ explant-derived cultures were used for the RNA isolation in one biological replicate. The concentration and quality of the isolated RNA was evaluated using an ND-1000 NanoDrop spectrophotometer (Nano Drop Technologies, LLC, Wilmington, DE, USA). The miRNA-specific and oligo-dT primers and RivertAid First Strand cDNA synthesis kit (Thermo Fisher Scientific, Waltham, MA, USA) were used to synthesise the cDNA. The mature miRNAs were identified according to Speth and Laubinger [84]. The product of the reverse transcription was diluted with water at a 1:4 ratio and $2.0 \mu \mathrm{L}$ of the solution was used for the Real-Time RT qPCR. LightCycler Fast-Start DNA Master SYBR Green I (Roche, Basel, Switzerland) and the primers that were relevant to the genes being studied were used to determine the Real-Time RT qPCR reactions (Supplementary Table S1 [85,86]). The Cp values were calculated using LinRegPCR software. The relative RNA and miRNA levels were calculated and normalised to an internal control, the At4g27090 gene encoded 60S ribosomal protein. The control gene had a constant expression pattern $\left(C_{T}=18 \pm 1\right)$ in all of the tissue samples that were analysed. The plant tissues for the real-time (RT) qPCR analysis were produced in three biological repetitions and two technical replicates of each repetition were carried out. The relative expression level was calculated using $2^{-\Delta \Delta C T}$, where $\Delta \Delta C_{p}$ represents $\Delta C_{T}$ reference condition $-\Delta C_{p}$ compared condition. 


\subsection{Chromatin Immunoprecipitation (ChIP)}

The Yelagandula et al. ChIP method [87] was used with some modifications. The conditions of de-/crosslinking and chromatin shearing were optimised for the plant material being analysed. Chromatin extracts were prepared from the cultured explants ( $50 \mathrm{mg}$ of tissue per ChIP) and then treated with $1 \%$ formaldehyde for $20 \mathrm{~min}$ on ice under a vacuum. The chromatin was sheared to a mean length of 500 bp by sonication (Bioruptor ${ }^{\circledR}$ Plus, Diagenode, Denville, NJ, USA) and the complex of proteins and DNA fragments was then immunoprecipitated using the polyclonal antibodies against the acetylated forms of histone H3 (2 $\mu$; Merck, St. Louis, MO, USA, Cat. no. 06-599). The DNA that was cross-linked to the immunoprecipitated proteins was reversed and analysed using qPCR and the gene-specific primers. A LightCycler 480 (Roche, Basel, Switzerland) real-time detection system was used to analyse the relative acetylation level of the chromatin associated with DCL1, HEN1, and SERRATE genes. The qPCR reaction was performed as described by [84]. The primers that were used in the qPCR were designed using Primer3Plus software (version 3, Molbi, Michelstand, Germany) (Supplementary Table S2). The genomic sequences that were analysed in the DCL1, HEN1, and SE genes were localised in the TSS + 300 bp region and included the AGL15-binding CArG motif (Supplementary Figure S1). The Cp values were calculated using LinRegPCR software (version 11, Academic Medical Centre, Amsterdam, The Netherlands). The ChIP-qPCR data were normalised using the percent input method. The H3ac level is presented as $2^{\text {(adjusted input-Cp }(x x \text { gene) }} \times 100 \%$. Three biological replicates and two technical replicates were analysed for each combination.

\subsection{Statistical Analysis}

The Student's $t$-test $(p<0.05)$ or a two-way ANOVA $(p<0.05)$ followed by Tukey's honestly significant difference test (Tukey HSD-test) $(p<0.05)$ were used to calculate any significant differences between the combinations. The graphs show the averages with the standard deviation (SD); the statistical analysis was performed using the medians.

\section{Conclusions}

The study demonstrated that AGL15 might control the abundance of miR156 during embryogenic induction through diverse regulatory pathways that involve the positive transcriptional regulation of MIR156 (MIR156h) and the containment of the abundance of mature miR156 via the downregulation of the miRNA biogenesis genes DCL1, SERRATE, and HEN1 (Figure 10).

Two histone deacetylases, HDAC6 and HDAC19, were postulated to contribute to the AGL15-mediated repression of miRNA biogenesis during somatic embryogenesis. However, histone acetylation might also regulate the transcription of the MIR genes including MIR156 [88]. Given that HDACs can also function as transcriptional activators of genes [89,90], the role of HDAC6/19 in the AGL15-mediated activation of the MIR genes (e.g., MIR156h) might also be expected. In support of such a scenario, a histone acetyltransferase, GCN5, besides repressing miRNA processing, was required for the expression of a subset of the MIR genes [63]. Interestingly, HDAC19 interacts with the transcriptional activator of the auxin-responsive genes specifically in the cells that have an elevated auxin concentration [91]. This finding suggests that HDAC19, similar to GCN5 [63], might control the abundance of miRNA in an auxin-induced embryogenic culture through the repression of a subset of the miRNA biogenesis genes and the activation of the MIR genes. The MIR-regulatory function of HDAC19 requires experimental verification.

Histone (de)acetylases may also regulate miRNA processing through changes in the acetylation status of the regulatory proteins of the microprocessor complex [92,93]. Whether histone acetylases/deacetylases (e.g., HDAC6 and 19) affect the proteins that control the miRNA pathways in an embryogenic culture remains to be revealed. 


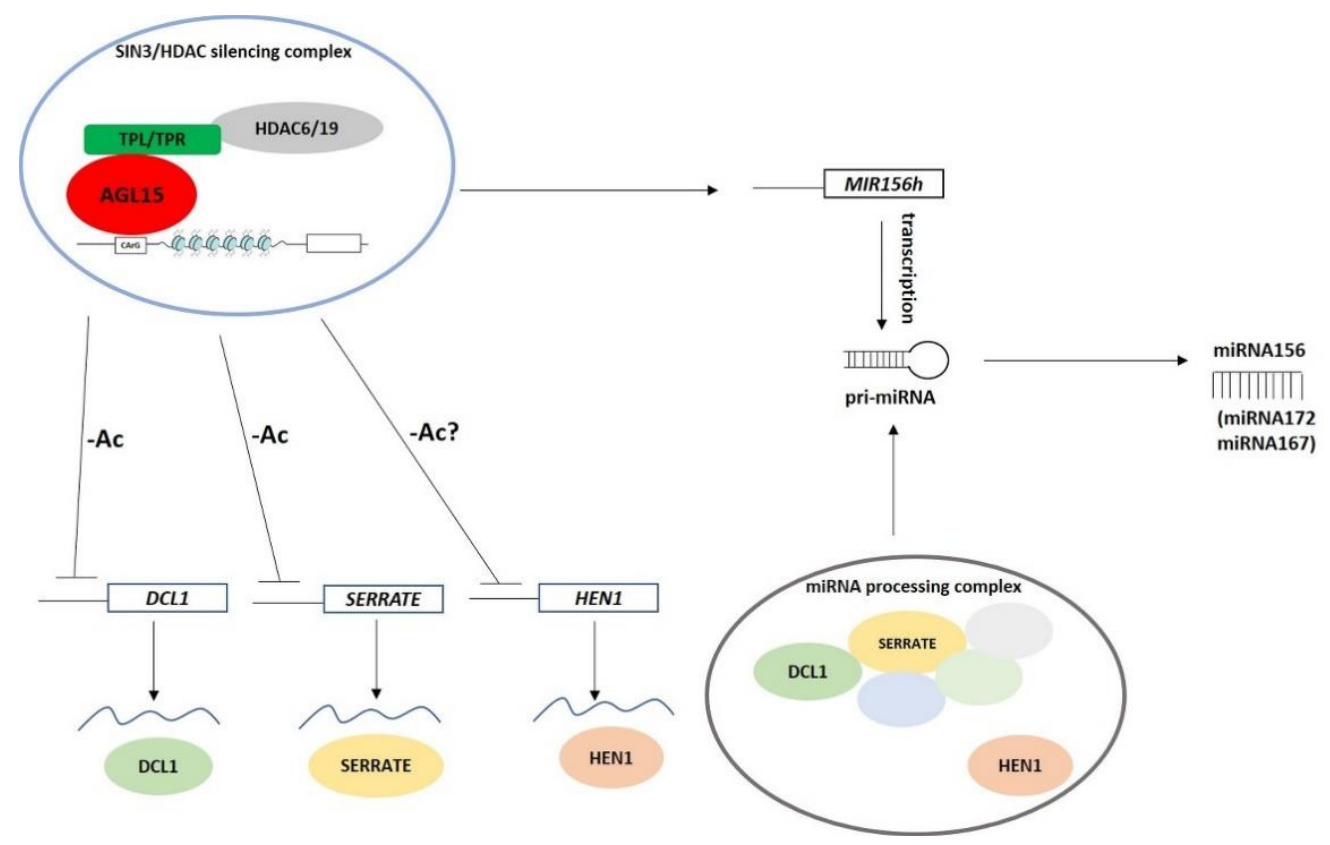

Figure 10. A putative model of the histone acetylation-related and AGL15-mediated control of miR156 during embryogenic induction. AGL15 is postulated to fine tune the abundance of miR156 by activating the MIR156 gene (MIR156h) expression and the containment of the mature miR156 molecules as a result of the repression of the miRNA biogenesis genes DCL1, SERRATE and HEN1. To repress the target genes, AGL15 interacts with the TOPLESS co-repressors (TPL, TPR1, TPR4) and recruits the histone deacetylases, HDAC6 and HDAC19, which are components of the SIN3/HDAC gene silencing complex [39,48]. The AGL15-mediated histone deacetylation might also control other miRNAs including miR167 and miR172 in embryogenic culture. AGL15-AGAMOUS-like15, DCL1-DICER-like1, HEN1-HUA-ENHANCER1, TPL-TOPLESS, TPR-TOPLESS-RELATED, HDAC-HISTONE DEACETHYLASE.

In conclusion, the present study indicates that similar to mouse and human cells [94,95], histone acetylation controls the miRNA pathways during the reprogramming of plant somatic cells to pluripotency and that AGL15 seems to play an essential regulatory role in this mechanism.

Supplementary Materials: Can be found at http://www.mdpi.com/1422-0067/21/18/6733/s1. Supplementary Figure S1. Localisation of the CArG sequence in the promoter region of the DCL1 (A), SERRATE (B) and HEN1 (C) genes. Green boxes indicate the presence of a CArG sequence and orange lines indicate the sequence that was amplified during the Real Time qPCR analysis after the ChIP analysis. Supplementary Figure S2. Level of mature miR172 and miR167 in the embryogenic cultures of the 35S::AGL15 and agl15 agl18 transgenic lines. The relative miRNA level was normalised to an internal control (At4g27090) and calibrated to the Col-0 culture of the same age. ${ }^{*}$ value significantly different from the 35S::AGL15 culture of the same age $(p<0.05 ; n=3 \pm \mathrm{SD})$. Supplementary Table S1. Primer's sequence used for gene expression analysis. Supplementary Table S2. Primer's sequences used in the ChIP analysis.

Author Contributions: K.N. and M.D.G. conceived and designed the experiments, analysed the data, and wrote the manuscript; K.N., J.M., and A.W. performed the experiments. All authors have read and agreed to the published version of the manuscript.

Funding: This work was supported by a research grant from the National Science Centre in Poland (OPUS13 2017/25/B/NZ1/01615).

Conflicts of Interest: The authors declare no conflict of interest. 


\section{Abbreviations}

$\begin{array}{ll}\text { AGL15 } & \text { AGAMOUS-like 15 } \\ \text { SE } & \text { somatic embryogenesis } \\ \text { TF } & \text { Transcription factor } \\ \text { TSS } & \text { Transcription start site } \\ \text { miRNA } & \text { microRNA } \\ \text { DCL1 } & \text { DICER-like1 } \\ \text { HEN1 } & \text { HUA-ENHANCER1 } \\ \text { HYL1 } & \text { HYPONASTIC LEAVES1 } \\ \text { TPL } & \text { TOPLESS } \\ \text { TPR } & \text { TOPLESS-RELATED } \\ \text { HDAC } & \text { HISTONE DEACETYLASE } \\ \text { TSA } & \text { Trichostatin A } \\ \text { ChIP } & \text { Chromatin immunoprecipitation } \\ \text { SIN3/HDAC } & \text { SWI-INDEPENDENT3/HISTONE DEACETYLASE }\end{array}$

\section{References}

1. Wójcik, A.M.; Wójcikowska, B.; Gaj, M.D. Current perspectives on the auxin-mediated genetic network that controls the induction of somatic embryogenesis in plants. Int. J. Mol. Sci. 2020, 21, 1333. [CrossRef]

2. Wójcikowska, B.; Wójcik, A.M.; Gaj, M.D. Epigenetic regulation of auxin-induced somatic embryogenesis in plants. Int. J. Mol. Sci. 2020, 21, 2307. [CrossRef] [PubMed]

3. Fehér, A. Callus, dedifferentiation, totipotency, somatic embryogenesis: What These Terms Mean in the Era of Molecular Plant Biology? Front. Plant Sci. 2019, 10, 536. [CrossRef] [PubMed]

4. Siddiqui, Z.H.; Abbas, Z.K.; Ansari, M.W.; Khan, M.N. The role of miRNA in somatic embryogenesis. Genomics 2019, 111, 1026-1033. [CrossRef] [PubMed]

5. Singla, B.; Tyagi, A.K.; Khurana, J.P.; Khurana, P. Analysis of expression profile of selected genes expressed during auxin-induced somatic embryogenesis in leaf base system of wheat (Triticum aestivum) and their possible interactions. Plant Mol. Biol. 2007, 65, 677-692. [CrossRef] [PubMed]

6. Imin, N.; Goffard, N.; Nizamidin, M.; Rolfe, B.G. Genome-wide transcriptional analysis of super-embryogenic Medicago truncatula explant cultures. BMC Plant Biol. 2008, 8, 1-14. [CrossRef]

7. Chakrabarty, D.; Trivedi, P.K.; Shri, M.; Misra, P.; Asif, M.H.; Dubey, S.; Kumar, S.; Rai, A.; Tiwari, M.; Shukla, D.; et al. Differential transcriptional expression following thidiazuron-induced callus differentiation developmental shifts in rice. Plant Biol. 2010, 12, 46-59. [CrossRef]

8. Gliwicka, M.; Nowak, K.; Balazadeh, S.; Mueller-Roeber, B.; Gaj, M.D. Extensive Modulation of the Transcription Factor Transcriptome during Somatic Embryogenesis in Arabidopsis thaliana. PLoS ONE 2013, 8, e69261. [CrossRef]

9. Wickramasuriya, A.M.; Dunwell, J.M. Global scale transcriptome analysis of Arabidopsis embryogenesis in vitro. BMC Genom. 2015, 16, 301. [CrossRef]

10. Wang, H.; Caruso, L.V.; Downie, A.B.; Perry, S.E. The Embryo MADS Domain Protein AGAMOUS-Like 15 Directly Regulates Expression of a Gene Encoding an Enzyme Involved in Gibberellin Metabolism. Plant Cell 2004, 16, 1206-1219. [CrossRef]

11. Harding, E.W. Expression and Maintenance of Embryogenic Potential is Enhanced through Constitutive Expression of AGAMOUS-Like 15. Plant Physiol. 2003, 133, 653-663. [CrossRef] [PubMed]

12. West, A.G.; Shore, P.; Sharrocks, A.D. DNA binding by MADS-box transcription factors a molecular mechanism for differential DNA bending. Mol. Cell. Biol. 1997, 17, 2876-2887. [CrossRef] [PubMed]

13. Zheng, Y.; Ren, N.; Wang, H.; Stromberg, A.J.; Perry, S.E. Global identification of targets of the Arabidopsis MADS domain protein AGAMOUS-Like15. Plant Cell 2009, 21, 2563-2577. [CrossRef] [PubMed]

14. Zheng, Q.; Zheng, Y.; Ji, H.; Burnie, W.; Perry, S.E. Gene regulation by the AGL15 transcription factor reveals hormone interactions in somatic embryogenesis. Plant Physiol. 2016, 172, 2374-2387. [CrossRef] [PubMed]

15. Thakare, D.; Tang, W.; Hill, K.; Perry, S.E. The MADS-Domain Transcriptional Regulator AGAMOUS-LIKE15 Promotes Somatic Embryo Development in Arabidopsis and Soybean. Plant Physiol. 2008, 146, 1663-1672. [CrossRef] 
16. Zheng, Q.; Zheng, Y.; Perry, S.E. Decreased GmAGL15 expression and reduced ethylene synthesis may contribute to reduced somatic embryogenesis in a poorly embryogenic cultivar of Glycine max. Plant Signal. Behav. 2013, 8, 8-11. [CrossRef]

17. Zheng, Q.; Perry, S.E. Alterations in the transcriptome of soybean in response to enhanced somatic embryogenesis promoted by orthologs of Agamous-like15 and Agamous-like18. Plant Physiol. 2014, 164, 1365-1377. [CrossRef]

18. Nowak, K.; Gaj, M.D. Transcription Factors in the Regulation of Somatic Embryogenesis BT-Somatic Embryogenesis: Fundamental Aspects and Applications; Loyola-Vargas, V.M., Ochoa-Alejo, N., Eds.; Springer: Berlin/Heidelberg, Germany, 2016; pp. 53-79. ISBN 978-3-319-33705-0.

19. Braybrook, S.A.; Stone, S.L.; Park, S.; Bui, A.Q.; Le, B.H.; Fischer, R.L.; Goldberg, R.B.; Harada, J.J. Genes directly regulated by leafy cotyledon2 provide insight into the control of embryo maturation and somatic embryogenesis. Proc. Natl. Acad. Sci. USA 2006, 103, 3468-3473. [CrossRef]

20. Horstman, A.; Li, M.; Heidmann, I.; Weemen, M.; Chen, B.; Muino, J.M.; Angenent, G.C.; Boutiliera, K. The BABY BOOM transcription factor activates the LEC1-ABI3-FUS3-LEC2 network to induce somatic embryogenesis. Plant Physiol. 2017, 175, 848-857. [CrossRef]

21. Serivichyaswat, P.; Ryu, H.-S.; Kim, W.; Kim, S.; Chung, K.S.; Kim, J.J.; Ahn, J.H. Expression of the floral repressor miRNA156 is positively regulated by the AGAMOUS-like proteins AGL15 and AGL18. Mol. Cells 2015, 38, 259-266. [CrossRef]

22. Bartel, D.P. MicroRNAs: Target Recognition and Regulatory Functions. Cell 2009, 136, 215-233. [CrossRef]

23. Hobert, O. Common logic of transcription factor and microRNA action. Trends Biochem. Sci. 2004, 29, 462-468. [CrossRef] [PubMed]

24. Jones-Rhoades, M.W.; Bartel, D.P.; Bartel, B. MicroRNAs and Their Regulatory Roles in Plants. Annu. Rev. Plant Biol. 2006, 57, 19-53. [CrossRef] [PubMed]

25. Li, T.; Chen, J.; Qiu, S.; Zhang, Y.; Wang, P.; Yang, L.; Lu, Y.; Shi, J. Deep Sequencing and Microarray Hybridization Identify Conserved and Species-Specific MicroRNAs during Somatic Embryogenesis in Hybrid Yellow Poplar. PLoS ONE 2012, 7, e43451. [CrossRef]

26. Zhang, Y.; Wiggins, B.; Lawrence, C.; Petrick, J.; Ivashuta, S.; Heck, G. Analysis of plant-derived miRNAs in animal small RNA datasets. BMC Genom. 2012, 13, 381. [CrossRef]

27. Yang, X.; Wang, L.; Yuan, D.; Lindsey, K.; Zhang, X. Small RNA and degradome sequencing reveal complex miRNA regulation during cotton somatic embryogenesis. J. Exp. Bot. 2013, 64, 1521-1536. [CrossRef] [PubMed]

28. Mongomake, K.; Doungous, O.; Khatabi, B.; Fondong, V.N. Somatic embryogenesis and plant regeneration of cassava (Manihot esculenta Crantz) landraces from Cameroon. SpringerPlus 2015, 4, 1-12. [CrossRef] [PubMed]

29. Chávez-Hernández, E.C.; Alejandri-Ramírez, N.D.; Juárez-González, V.T.; Dinkova, T.D. Maize miRNA and target regulation in response to hormone depletion and light exposure during somatic embryogenesis. Front. Plant Sci. 2015, 6, 555. [CrossRef] [PubMed]

30. Szyrajew, K.; Bielewicz, D.; Dolata, J.; Wójcik, A.M. MicroRNAs Are Intensively Regulated during Induction of Somatic Embryogenesis in Arabidopsis. Front. Plant Sci. 2017, 8, 18. [CrossRef] [PubMed]

31. Wójcik, A.M.; Gaj, M.D. MiR393 contributes to the embryogenic transition induced in vitro in Arabidopsis via the modification of the tissue sensitivity to auxin treatment. Planta 2016, 244, 231-243. [CrossRef]

32. Wójcik, A.M.; Nodine, M.D.; Gaj, M.D. MiR160 and miR166/165 contribute to the LEC2-mediated auxin response involved in the somatic embryogenesis induction in Arabidopsis. Front. Plant Sci. 2017, 8, 2024. [CrossRef] [PubMed]

33. Szczygieł-Sommer, A.; Gaj, M.D. The miR396-GRF regulatory module controls the embryogenic response in Arabidopsis via an auxin-related pathway. Int. J. Mol. Sci. 2019, 20, 5221. [CrossRef] [PubMed]

34. Wu, X.M.; Liu, M.Y.; Ge, X.X.; Xu, Q.; Guo, W.W. Stage and tissue-specific modulation of ten conserved miRNAs and their targets during somatic embryogenesis of Valencia sweet orange. Planta 2011, 233, 495-505. [CrossRef] [PubMed]

35. Lin, Y.; Lai, Z. Comparative Analysis Reveals Dynamic Changes in miRNAs and Their Targets and Expression during Somatic Embryogenesis in Longan (Dimocarpus longan Lour.). PLoS ONE 2013, 8, e60337. [CrossRef] [PubMed] 
36. Chen, C.J.; Liu, Q.; Zhang, Y.C.; Qu, L.H.; Chen, Y.Q.; Gautheret, D. Genome-wide discovery and analysis of microRNAs and other small RNAs from rice embryogenic callus. RNA Biol. 2011, 8, 538-547. [CrossRef]

37. Xie, M.; Zhang, S.; Yu, B. MicroRNA biogenesis, degradation and activity in plants. Cell. Mol. Life Sci. 2015, 72, 87-99. [CrossRef]

38. Kurczyńska, E.U.; Gaj, M.D.; Ujczak, A.; Mazur, E. Histological analysis of direct somatic embryogenesis in Arabidopsis thaliana (L.) Heynh. Planta 2007, 226, 619-628. [CrossRef]

39. Causier, B.; Ashworth, M.; Guo, W.; Davies, B. The TOPLESS Interactome: A Framework for Gene Repression in Arabidopsis. Plant Physiol. 2012, 158, 423-438. [CrossRef]

40. Long, J.A.; Ohno, C.; Smith, Z.R.; Meyerowitz, E.M. TOPLESS regulates apical embryonic fate in Arabidopsis. Science 2006, 312, 1520-1523. [CrossRef]

41. Kagale, S.; Rozwadowski, K. EAR motif-mediated transcriptional repression in plants: An underlying mechanism for epigenetic regulation of gene expression. Epigenetics 2011, 6, 141-146. [CrossRef]

42. Wang, Z.; Cao, H.; Chen, F.; Liu, Y. The roles of histone acetylation in seed performance and plant development. Plant Physiol. Biochem. 2014, 84, 125-133. [CrossRef] [PubMed]

43. Gaj, M.D.; Zhang, S.; Harada, J.J.; Lemaux, P.G. Leafy cotyledon genes are essential for induction of somatic embryogenesis of Arabidopsis. Planta 2005, 222, 977-988. [CrossRef] [PubMed]

44. Zhou, Y.; Tan, B.; Luo, M.; Li, Y.; Liu, C.; Chen, C.; Yu, C.W.; Yang, S.; Dong, S.; Ruan, J.; et al. HISTONE DEACETYLASE19 interacts with HSL1 and participates in the repression of seed maturation genes in Arabidopsis seedlings. Plant Cell 2013, 25, 134-148. [CrossRef] [PubMed]

45. Chhun, T.; Chong, S.Y.; Park, B.S.; Wong, E.C.C.; Yin, J.L.; Kim, M.; Chua, N.H. HSI2 repressor recruits MED13 and HDA6 to down-regulate seed maturation gene expression directly during Arabidopsis early seedling growth. Plant Cell Physiol. 2016, 57, 1689-1706. [CrossRef] [PubMed]

46. Krogan, N.T.; Hogan, K.; Long, J.A. APETALA2 negatively regulates multiple floral organ identity genes in Arabidopsis by recruiting the co-repressor TOPLESS and the histone deacetylase HDA19. Development 2012, 139, 4180-4190. [CrossRef]

47. Tanaka, M.; Kikuchi, A.; Kamada, H. The Arabidopsis histone deacetylases HDA6 and HDA19 contribute to the repression of embryonic properties after germination. Plant Physiol. 2008, 146, 149-161. [CrossRef]

48. Hill, K.; Wang, H.; Perry, S.E. A transcriptional repression motif in the MADS factor AGL15 is involved in recruitment of histone deacetylase complex components. Plant J. 2008, 53, 172-185. [CrossRef]

49. Zhu, A.; Greaves, I.K.; Dennis, E.S.; Peacock, W.J. Genome-wide analyses of four major histone modifications in Arabidopsis hybrids at the germinating seed stage. BMC Genom. 2017, 18, 1-9. [CrossRef]

50. Wang, L.; Zhang, F.; Rode, S.; Chin, K.K.; Ko, E.E.; Kim, J.; Iyer, V.R.; Qiao, H. Ethylene induces combinatorial effects of histone H3 acetylation in gene expression in Arabidopsis. BMC Genom. 2017, 18, 1-13. [CrossRef]

51. Barciszewska-Pacak, M.; Milanowska, K.; Knop, K.; Bielewicz, D.; Nuc, P.; Plewka, P.; Pacak, A.M.; Vazquez, F.; Karlowski, W.; Jarmolowski, A.; et al. Arabidopsis microRNA expression regulation in a wide range of abiotic stress responses. Front. Plant Sci. 2015, 6, 1-14. [CrossRef]

52. Perry, S.E.; Zheng, Q.; Zheng, Y. Transcriptome analysis indicates that GmAGAMOUS-Like 15 may enhance somatic embryogenesis by promoting a dedifferentiated state. Plant Signal. Behav. 2016, 11, 1-7. [CrossRef] [PubMed]

53. Zavattieri, M.A.; Frederico, A.M.; Lima, M.; Sabino, R.; Arnholdt-Schmitt, B. Induction of somatic embryogenesis as an example of stress-related plant reactions. Electron. J. Biotechnol. 2010, 13, 1-9. [CrossRef]

54. Wang, F.; Perry, S.E. Identification of direct targets of FUSCA3, a key regulator of Arabidopsis seed development. Plant Physiol. 2013, 161, 1251-1264. [CrossRef]

55. Yant, L.; Mathieu, J.; Dinh, T.T.; Ott, F.; Lanz, C.; Wollmann, H.; Chen, X.; Schmid, M. Orchestration of the floral transition and floral development in Arabidopsis by the bifunctional transcription factor APETALA2. Plant Cell 2010, 22, 2156-2170. [CrossRef] [PubMed]

56. De Folter, S.; Immink, R.G.H.; Kieffer, M.; Pařenicová, L.; Henz, S.R.; Weigel, D.; Busscher, M.; Kooiker, M.; Colombo, L.; Kater, M.M.; et al. Comprehensive interaction map of the Arabidopsis MADS box transcription factors. Plant Cell 2005, 17, 1424-1433. [CrossRef]

57. Wójcikowska, B. (University of Silesia, Katowice, Poland); Chwiałkowska, K. (Medical University of Bialystok, Białystok, Poland); Gaj, M.D. (University of Silesia, Katowice, Poland). Personal communication, 2020. 
58. Zhang, S.; Liu, Y.; Yu, B. New insights into pri-miRNA processing and accumulation in plants. Wiley Interdiscip. Rev. RNA 2015, 6, 533-545. [CrossRef]

59. Ramachandran, V.; Chen, X. Small RNA metabolism in Arabidopsis. Trends Plant Sci. 2009, 13, 368-374. [CrossRef]

60. Köster, T.; Meyer, K.; Weinholdt, C.; Smith, L.M.; Lummer, M.; Speth, C.; Grosse, I.; Weigel, D.; Staiger, D. Regulation of pri-miRNA processing by the hnRNP-like protein AtGRP7 in Arabidopsis. Nucleic Acids Res. 2014, 42, 9925-9936. [CrossRef]

61. Dolata, J.; Bajczyk, M.; Bielewicz, D.; Niedojadlo, K.; Niedojadlo, J.; Pietrykowska, H.; Walczak, W.; Szweykowska-Kulinska, Z.; Jarmolowski, A. Salt stress reveals a new role for ARGONAUTE1 in miRNA biogenesis at the transcriptional and posttranscriptional levels. Plant Physiol. 2016, 172, 297-312. [CrossRef]

62. Wang, J.; Mei, J.; Ren, G. Plant microRNAs: Biogenesis, homeostasis, and degradation. Front. Plant Sci. 2019, 10, 1-12. [CrossRef]

63. Kim, W.; Benhamed, M.; Servet, C.; Latrasse, D.; Zhang, W.; Delarue, M.; Zhou, D.X. Histone acetyltransferase GCN5 interferes with the miRNA pathway in Arabidopsis. Cell Res. 2009, 19, 899-909. [CrossRef]

64. Ke, J.; Ma, H.; Gu, X.; Thelen, A.; Brunzelle, J.S.; Li, J.; Xu, H.E.; Melcher, K. Structural basis for recognition of diverse transcriptional repressors by the TOPLESS family of corepressors. Sci. Adv. 2015, 1, e1500107. [CrossRef] [PubMed]

65. Lee, M.S.; An, J.H.; Cho, H.T. Biological and molecular functions of two EAR motifs of Arabidopsis IAA7. J. Plant Biol. 2016, 59, 24-32. [CrossRef]

66. Kuhn, A.; Harborough, S.R.; McLaughlin, H.M.; Natarajan, B.; Verstraeten, I.; Friml, J.; Kepinski, S.; Østergaard, L. Direct ETTIN-auxin interaction controls chromatin states in gynoecium development. eLife 2020, 9, e51787. [CrossRef]

67. Leydon, A.R.; Wang, W.; Juarez-Solis, S.; Zemke, J.E.; Zahler, M.L.; Zheng, N.; Nemhauser, J.L. Structure-function analysis of Arabidopsis TOPLESS reveals conservation of repression mechanisms across eukaryotes. bioRxiv 2020. [CrossRef]

68. Zuo, J.; Niu, Q.W.; Frugis, G.; Chua, N.H. The WUSCHEL gene promotes vegetative-to-embryonic transition in Arabidopsis. Plant J. 2002, 30, 349-359. [CrossRef] [PubMed]

69. Palovaara, J.; Hallberg, H.; Stasolla, C.; Hakman, I. Comparative expression pattern analysis of WUSCHEL-related homeobox 2 (WOX2) and WOX8/9 in developing seeds and somatic embryos of the gymnosperm Picea abies. New Phytol. 2010, 188, 122-135. [CrossRef]

70. Su, Y.H.; Liu, Y.B.; Bai, B.; Zhang, X.S. Establishment of embryonic shoot-root axis is involved in auxin and cytokinin response during Arabidopsis somatic embryogenesis. Front. Plant Sci. 2015, 5. [CrossRef]

71. Wójcikowska, B.; Gaj, M.D. Expression profiling of Auxin Response Factor genes during somatic embryogenesis induction in Arabidopsis. Plant Cell Rep. 2017, 36, 843-858. [CrossRef]

72. Quintana-Escobar, A.O.; Nic-Can, G.I.; Avalos, R.M.G.; Loyola-Vargas, V.M.; Gongora-Castillo, E. Transcriptome analysis of the induction of somatic embryogenesis in Coffea canephora and the participation of ARF and Aux/IAA genes. PeerJ 2019, 2019, e7752. [CrossRef]

73. Boutilier, K. Ectopic Expression of BABY BOOM Triggers a Conversion from Vegetative to Embryonic Growth. Plant Cell Online 2002, 14, 1737-1749. [CrossRef] [PubMed]

74. Blázquez, M.A.; Nelson, D.C.; Weijers, D. Evolution of Plant Hormone Response Pathways. Annu. Rev. Plant Biol. 2020, 71, 327-353. [CrossRef] [PubMed]

75. Yu, C.W.; Liu, X.; Luo, M.; Chen, C.; Lin, X.; Tian, G.; Lu, Q.; Cui, Y.; Wu, K. Histone Deacetylase6 interacts with Flowering Locus D and regulates flowering in Arabidopsis. Plant Physiol. 2011, 156, 173-184. [CrossRef] [PubMed]

76. Yu, Y.; Jia, T.; Chen, X. The "how" and "where" of plant microRNAs. New Phytol. 2017, 216, 1002-1017. [CrossRef] [PubMed]

77. Liu, X.; Yu, C.W.; Duan, J.; Luo, M.; Wang, K.; Tian, G.; Cui, Y.; Wu, K. HDA6 Directly interacts with DNA methyltransferase MET1 and maintains transposable element silencing in Arabidopsis. Plant Physiol. 2012, 158, 119-129. [CrossRef]

78. To, T.K.; Kim, J.-M.; Matsui, A.; Kurihara, Y.; Morosawa, T.; Ishida, J.; Tanaka, M.; Endo, T.; Kakutani, T.; Toyoda, T.; et al. Arabidopsis HDA6 Regulates Locus-Directed Heterochromatin Silencing in Cooperation with MET1. PLoS Genet. 2011, 7, 1-14. [CrossRef] 
79. Wójcikowska, B.; Botor, M.; Morończyk, J.; Wójcik, A.M.; Nodzyński, T.; Karcz, J.; Gaj, M.D. Trichostatin A triggers an embryogenic transition in Arabidopsis explants via an auxin-related pathway. Front. Plant Sci. 2018, 9, 1-19. [CrossRef]

80. Liu, X.; Yang, S.; Zhao, M.; Luo, M.; Yu, C.W.; Chen, C.Y.; Tai, R.; Wu, K. Transcriptional repression by histone deacetylases in plants. Mol. Plant 2014, 7, 764-772. [CrossRef]

81. Kim, J.-Y.; Yang, W.; Forner, J.; Lohmann, J.U.; Noh, B.; Noh, Y.-S. Epigenetic reprogramming by histone acetyltransferase HAG1/AtGCN5 is required for pluripotency acquisition in Arabidopsis. EMBO J. 2018, 37, e98726. [CrossRef]

82. Gaj, M.D. Direct somatic embryogenesis as a rapid and efficient system for in vitro regeneration of Arabidopsis thaliana. Plant Cell. Tissue Organ Cult. 2001, 64, 39-46. [CrossRef]

83. Gamborg, O.L.; Miller, R.A.; Ojima, K. Nutrient requirements of suspension cultures of soybean root cells. Exp. Cell Res. 1968, 50, 151-158. [CrossRef]

84. Speth, C.; Laubinger, S. Rapid and Parallel Quantification of Small and Large RNA Species. In Plant Circadian Networks: Methods and Protocols; Staiger, D., Ed.; Springer: New York, NY, USA, 2014; pp. 93-106. ISBN 978-1-4939-0700-7.

85. Nowak, K.; Wójcikowska, B.; Gaj, M.D. ERF022 impacts the induction of somatic embryogenesis in Arabidopsis through the ethylene-related pathway. Planta 2015, 241, 967-985. [CrossRef] [PubMed]

86. Grzybkowska, D.; Morończyk, J.; Wójcikowska, B.; Gaj, M.D. Azacitidine (5-AzaC)-treatment and mutations in DNA methylase genes affect embryogenic response and expression of the genes that are involved in somatic embryogenesis in Arabidopsis. Plant Growth Regul. 2018, 85, 243-256. [CrossRef]

87. Yelagandula, R.; Osakabe, A.; Axelsson, E.; Berger, F.; Kawashima, T. Genome-Wide Profiling of Histone Modifications and Histone Variants in Arabidopsis thaliana and Marchantia polymorpha. In Plant Genomics: Methods and Protocols; Busch, W., Ed.; Springer: New York, NY, USA, 2017; pp. 93-106. ISBN 978-1-4939-7003-2.

88. Xu, Y.; Zhang, L.; Wu, G. Epigenetic regulation of juvenile-to-adult transition in plants. Front. Plant Sci. 2018, 9, 1048. [CrossRef] [PubMed]

89. Kurdistani, S.K.; Tavazoie, S.; Grunstein, M. Mapping global histone acetylation patterns to gene expression. Cell 2004, 117, 721-733. [CrossRef] [PubMed]

90. Zupkovitz, G.; Tischler, J.; Posch, M.; Sadzak, I.; Ramsauer, K.; Egger, G.; Grausenburger, R.; Schweifer, N.; Chiocca, S.; Decker, T.; et al. Negative and Positive Regulation of Gene Expression by Mouse Histone Deacetylase1. Mol. Cell. Biol. 2006, 26, 7913-7928. [CrossRef]

91. Gao, M.J.; Parkin, I.A.P.; Lydiate, D.J.; Hannoufa, A. An auxin-responsive SCARECROW-like transcriptional activator interacts with histone deacetylase. Plant Mol. Biol. 2004, 55, 417-431. [CrossRef]

92. Wada, T.; Kikuchi, J.; Furukawa, Y. Histone deacetylase 1 enhances microRNA processing via deacetylation of DGCR8. EMBO Rep. 2012, 13, 142-149. [CrossRef]

93. Tang, X.; Wen, S.; Zheng, D.; Tucker, L.; Cao, L.; Pantazatos, D.; Moss, S.F.; Ramratnam, B. Acetylation of Drosha on the N-Terminus Inhibits Its Degradation by Ubiquitination. PLoS ONE 2013, 8, e72503. [CrossRef]

94. Anokye-Danso, F.; Trivedi, C.M.; Juhr, D.; Gupta, M.; Cui, Z.; Tian, Y.; Zhang, Y.; Yang, W.; Gruber, P.J.; Epstein, J.A.; et al. Highly efficient miRNA-mediated reprogramming of mouse and human somatic cells to pluripotency. Cell Stem Cell 2011, 8, 376-388. [CrossRef]

95. Anokye-Danso, F.; Snitow, M.; Morrisey, E.E. How microRNAs facilitate reprogramming to pluripotency. J. Cell Sci. 2012, 125, 4179-4787. [CrossRef] [PubMed]

(C) 2020 by the authors. Licensee MDPI, Basel, Switzerland. This article is an open access article distributed under the terms and conditions of the Creative Commons Attribution (CC BY) license (http://creativecommons.org/licenses/by/4.0/). 